\title{
INHERITANCE OF SHELL SIZE IN PARTULA
}

\author{
JAMES MURRAY \\ Department of Biology, University of Virginia \\ and \\ BRYAN CLARKE \\ Department of Zoology, University of Edinburgh
}

Received 6.vi.67

\section{Introduction}

Studies of the land snails of the genus Partula have emphasised two aspects of the variation in this remarkable group. On the one hand, the polymorphism of shell colour and pattern has attracted the attention of collectors from the earliest discovery of these animals (Capt. J. Cook, unpubl.; Hartman, 1885; Garrett, 1884). On the other hand, interest in the variation of size and shape of the shells dates from the classic researches of Crampton (1916, 1925, 1932).

Crampton's massive accumulations of biometrical data from the species inhabiting the island of Moorea have served as the basis for a number of derivative analyses (Lundman, 1947; Bailey, 1956). Implicit in all this work has been the assumption that the variation of shell size in Partula is under genetic control. In this paper we present evidence, from breeding experiments with Partula taeniata Mörch and Partula suturalis Pfeiffer, that there is indeed a high degree of heritability of size.

\section{Materials AND methods}

The families* on which this study is based are the $F_{1}$ and the $F_{2}$ offspring of individuals collected on the island of Moorea in 1962. The parents fall conveniently into two groups, those collected in the wild as half-grown, sexually immature individuals, and those reared entirely in the laboratory. We have described elsewhere the methods of rearing, the special problems of mutual fertilisation, ovoviviparity and occasional self-fertilisation, and some of the genetics of the shell polymorphism (Murray and Clarke, 1966).

The basic data for this study are individual measurements of length and width. These were made with vernier calipers to the nearest $0.1 \mathrm{~mm}$. In determining the length of the shell we have used the standard conchological measurement, taken parallel to the columella and including the lip. The lengths are therefore exactly comparable to those of Crampton. In determining width, however, we have departed from the usual practice for two compelling reasons. First, we wished to use a measurement that is independent of the degree of flaring of the lip. Second, we have found that the usual measurement (perpendicular to length) is difficult to repeat reliably. We therefore chose to measure the width perpendicular to a line tangent to the last two whorls, just proximal to the lip. This procedure can be carried out quickly and with a high degree of repeatability (see fig. 1).

* For convenience the symbols $P, F_{1}$ and $F_{2}$ are used to refer to the parental generations and their first and second generation hybrids, but the parents represent populations rather than inbred lines. 
190

J. MURRAY AND B. CLARKE

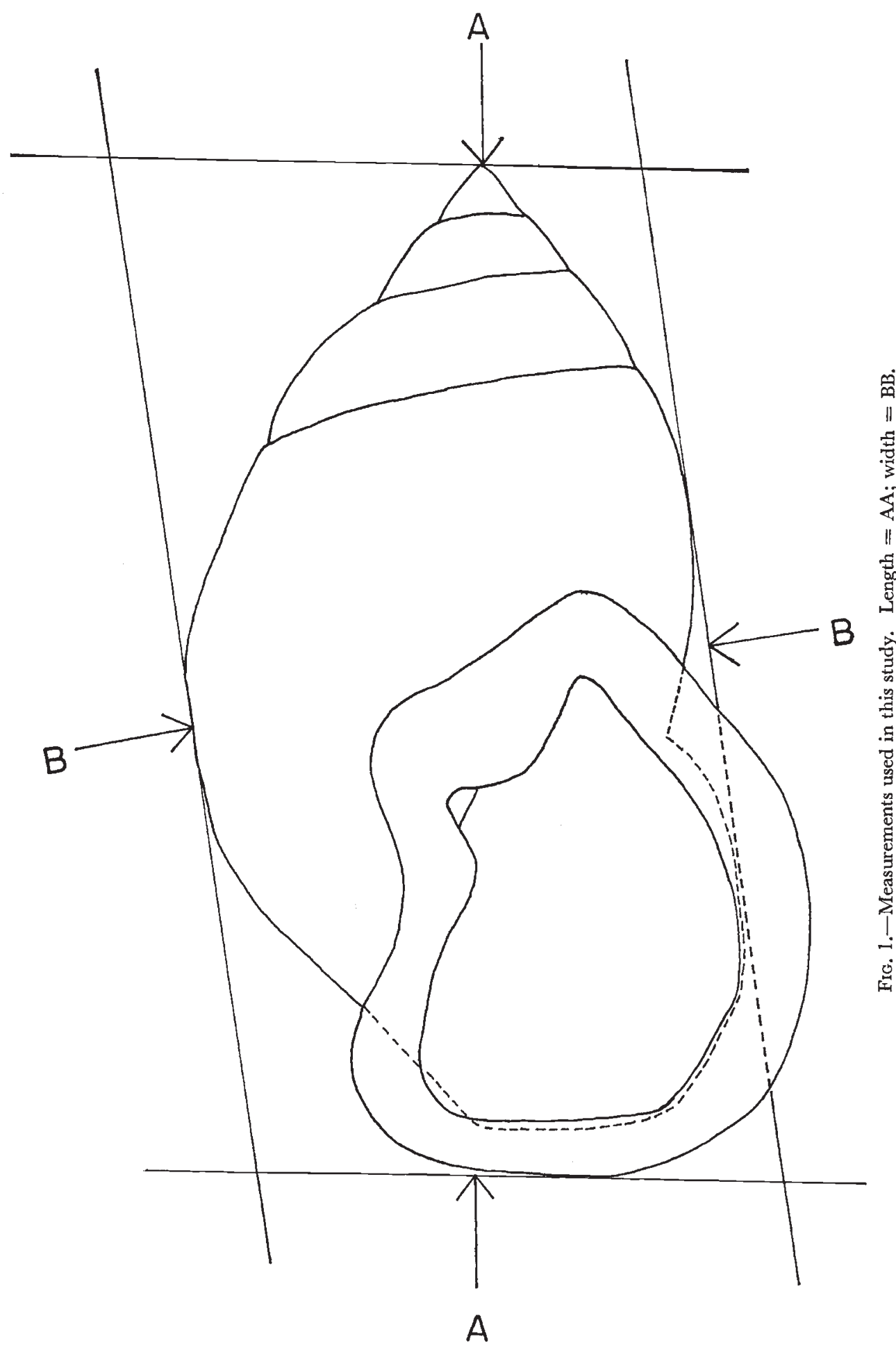


In both species we have measured all families with five or more offspring. The mid-points of the parents and the means of the offspring are shown for $P$. suturalis in table 1 and for $P$. taeniata in table 2 .

TABLE 1

Partula suturalis: $a$ list of matings showing the number of offspring and mean lengths and widths of parents and offspring for each mating

\begin{tabular}{|c|c|c|c|c|c|}
\hline \multirow{3}{*}{$\begin{array}{l}\text { Mating } \\
\text { number }\end{array}$} & \multirow{3}{*}{$\begin{array}{l}\text { Number of } \\
\text { offspring }\end{array}$} & \multirow{2}{*}{\multicolumn{2}{|c|}{ Mid-parent }} & \multicolumn{2}{|c|}{ Offspring } \\
\hline & & & & Mean & Mean \\
\hline & & Length & Width & length & width \\
\hline 20 & 36 & $19 \cdot 9$ & $10 \cdot 1$ & $19 \cdot 4$ & $9 \cdot 6$ \\
\hline 21 & 22 & 18.9 & $10 \cdot 1$ & $19 \cdot 0$ & $9 \cdot 8$ \\
\hline 22 & 18 & $19 \cdot 8$ & $9 \cdot 2$ & $19 \cdot 2$ & $8 \cdot 8$ \\
\hline 23 & 7 & $19 \cdot 6$ & $9 \cdot 3$ & $18 \cdot 3$ & $9 \cdot 0$ \\
\hline 24 & 11 & $18 \cdot 7$ & $9 \cdot 7$ & $19 \cdot 1$ & $9 \cdot 7$ \\
\hline 25 & 19 & $20 \cdot 7$ & $9 \cdot 6$ & $21 \cdot 3$ & $9 \cdot 1$ \\
\hline 26 & 31 & $19 \cdot 2$ & $9 \cdot 4$ & $18 \cdot 7$ & $9 \cdot 0$ \\
\hline 27 & 18 & $20 \cdot 0$ & $9 \cdot 1$ & $19 \cdot 9$ & $8 \cdot 6$ \\
\hline 28 & 12 & $20 \cdot 3$ & $10 \cdot 0$ & $21 \cdot 6$ & $9 \cdot 4$ \\
\hline 29 & 6 & $18 \cdot 6$ & $9 \cdot 4$ & $18 \cdot 3$ & $9 \cdot 0$ \\
\hline 83 & 11 & $19 \cdot 8$ & $9 \cdot 9$ & $17 \cdot 8$ & $9 \cdot 0$ \\
\hline 84 & 5 & $20 \cdot 3$ & $10 \cdot 0$ & $18 \cdot 9$ & $9 \cdot 8$ \\
\hline 85 & 5 & $21 \cdot 2$ & $9 \cdot 4$ & $20 \cdot 3$ & $9 \cdot 1$ \\
\hline 86 & 6 & $20 \cdot 4$ & $10 \cdot 2$ & $19 \cdot 3$ & $9 \cdot 3$ \\
\hline 87 & 13 & $18 \cdot 5$ & $10 \cdot 0$ & $17 \cdot 5$ & $9 \cdot 4$ \\
\hline 88 & 15 & $19 \cdot 4$ & $9 \cdot 0$ & $17 \cdot 4$ & $9 \cdot 0$ \\
\hline 89 & 14 & $20 \cdot 7$ & 8.7 & $20 \cdot 7$ & $9 \cdot 2$ \\
\hline 91 & 10 & $21 \cdot 2$ & $9 \cdot 9$ & $19 \cdot 3$ & $9 \cdot 5$ \\
\hline 92 & 7 & $20 \cdot 7$ & $9 \cdot 6$ & $19 \cdot 1$ & $9 \cdot 0$ \\
\hline 108 & 10 & $20 \cdot 1$ & $9 \cdot 0$ & $18 \cdot 5$ & $9 \cdot 1$ \\
\hline 114 & 5 & $21 \cdot 4$ & $9 \cdot 8$ & $20 \cdot 2$ & $9 \cdot 9$ \\
\hline
\end{tabular}

\section{ANALysis AND DISGUSSION}

Heritability $\left(h^{2}\right)$ is defined as the ratio of the additive genetic variance to the total phenotypic variance of a character. Since the phenotypic variance includes a component of environmental variance, heritability values are specific for the particular set of conditions under consideration.

Heritability may be estimated by employing either the correlation between relatives or the regression of offspring on one or both parents. The choice of methods depends on the types of available individuals, the magnitude of the heritability, the environmental sources of covariance, and the degree of similarity between parents (Falconer, 1960).

There are two possible sources of correlation between parents in our matings. First, in sixteen of the matings with wild-caught parents, both individuals came from the same geographical area. Since size varies from place to place (Clarke and Murray, in preparation), these animals could be more alike than randomly chosen ones. Second, all but six of the matings of lab-reared parents were between sibs. We have tested the correlation between parents in both groups of each species. In no case do the wildcaught parents show significant correlations of length or width. However, in the lab-reared groups, length in $P$. taeniata and width in $P$. suturalis show significant positive correlations between parents $(\mathrm{P}<0.001$ and $\mathrm{P}<0.05$ respectively). The other two associations were not significant. 
Our choice of parents, made on other grounds, has therefore resulted in a moderate amount of positive assortative mating. In this case the most satisfactory measure of heritability is the regression of the mean of the

TABle 2

Partula taeniata: a list of matings showing the number of offspring and mean lengths and widths of parents and offspring for each mating

\begin{tabular}{|c|c|c|c|c|c|}
\hline \multirow{3}{*}{$\begin{array}{l}\text { Mating } \\
\text { number }\end{array}$} & \multirow{3}{*}{$\begin{array}{l}\text { Number of } \\
\text { offspring }\end{array}$} & \multirow{2}{*}{\multicolumn{2}{|c|}{ Mid-parent }} & \multicolumn{2}{|c|}{ Offspring } \\
\hline & & & & Mean & Mean \\
\hline & & Length & Width & & \\
\hline 2 & 50 & $15 \cdot 8$ & $8 \cdot 1$ & $14 \cdot 6$ & $7 \cdot 8$ \\
\hline 3 & 31 & $15 \cdot 3$ & $7 \cdot 7$ & $15 \cdot 0$ & $7 \cdot 6$ \\
\hline 4 & 47 & $15 \cdot 5$ & $7 \cdot 8$ & 14.5 & $7 \cdot 5$ \\
\hline 5 & 13 & $15 \cdot 4$ & 7.9 & 14.5 & $7 \cdot 6$ \\
\hline 6 & 41 & $15 \cdot 3$ & 8.0 & 14.9 & $7 \cdot 7$ \\
\hline 7 & 37 & 14.8 & $7 \cdot 3$ & $15 \cdot 5$ & $7 \cdot 3$ \\
\hline 8 & 37 & $16 \cdot 4$ & $8 \cdot 0$ & $15 \cdot 7$ & $7 \cdot 9$ \\
\hline 10 & 34 & $15 \cdot 5$ & $7 \cdot 5$ & $16 \cdot 2$ & $7 \cdot 6$ \\
\hline 11 & 9 & $15 \cdot 1$ & $7 \cdot 5$ & $16 \cdot 2$ & $7 \cdot 5$ \\
\hline 12 & 28 & 14.5 & 7.9 & 14.5 & $7 \cdot 7$ \\
\hline 14 & 18 & $15 \cdot 6$ & $7 \cdot 8$ & $15 \cdot 1$ & $7 \cdot 8$ \\
\hline 15 & 28 & $14 \cdot 3$ & $7 \cdot 6$ & $15 \cdot 0$ & $7 \cdot 7$ \\
\hline 16 & 11 & $15 \cdot 2$ & $7 \cdot 7$ & $15 \cdot 3$ & 7.9 \\
\hline 17 & 16 & $14 \cdot 6$ & $7 \cdot 3$ & $14 \cdot 9$ & $7 \cdot 2$ \\
\hline 18 & 31 & $14 \cdot 3$ & $7 \cdot 3$ & $14 \cdot 4$ & $7 \cdot 4$ \\
\hline 56 & 40 & 13.9 & $7 \cdot 5$ & $14 \cdot 3$ & $7 \cdot 7$ \\
\hline 57 & 20 & $15 \cdot 4$ & $7 \cdot 6$ & $15 \cdot 2$ & $7 \cdot 7$ \\
\hline 58 & 31 & $13 \cdot 6$ & $7 \cdot 5$ & $14 \cdot 3$ & $7 \cdot 4$ \\
\hline 59 & 23 & $14 \cdot 5$ & $7 \cdot 5$ & $14 \cdot 8$ & $7 \cdot 8$ \\
\hline 61 & 36 & $14 \cdot 2$ & $6 \cdot 8$ & $15 \cdot 1$ & $7 \cdot 3$ \\
\hline 63 & 13 & $15 \cdot 1$ & $7 \cdot 8$ & $15 \cdot 2$ & 7.9 \\
\hline 64 & 24 & $15 \cdot 5$ & $8 \cdot 0$ & $15 \cdot 1$ & $7 \cdot 8$ \\
\hline 66 & 15 & 14.5 & $7 \cdot 4$ & 14.5 & $7 \cdot 7$ \\
\hline 67 & 18 & $15 \cdot 3$ & $7 \cdot 8$ & $15 \cdot 1$ & $7 \cdot 6$ \\
\hline 68 & 14 & $14 \cdot 8$ & $7 \cdot 6$ & $14 \cdot 6$ & 7.9 \\
\hline 69 & 10 & $16 \cdot 4$ & $8 \cdot 1$ & $15 \cdot 2$ & $7 \cdot 8$ \\
\hline 70 & 14 & $17 \cdot 6$ & 7.9 & $15 \cdot 4$ & $7 \cdot 7$ \\
\hline 71 & 17 & 15.5 & 7.9 & $15 \cdot 1$ & $7 \cdot 7$ \\
\hline 72 & 17 & $15 \cdot 3$ & $8 \cdot 1$ & $15 \cdot 3$ & $7 \cdot 9$ \\
\hline 73 & 7 & $14 \cdot 5$ & $7 \cdot 8$ & 13.9 & 7.5 \\
\hline 74 & 25 & $15 \cdot 8$ & $7 \cdot 5$ & $15 \cdot 6$ & $7 \cdot 6$ \\
\hline 75 & 22 & $17 \cdot 1$ & $8 \cdot 5$ & 15.9 & $8 \cdot 1$ \\
\hline 77 & 28 & $16 \cdot 5$ & 6.9 & 16.5 & $7 \cdot 4$ \\
\hline 78 & 22 & $14 \cdot 8$ & $7 \cdot 5$ & $14 \cdot 4$ & $7 \cdot 3$ \\
\hline 111 & 6 & 13.3 & 6.9 & $14 \cdot 3$ & $7 \cdot 6$ \\
\hline 113 & 9 & $14 \cdot 3$ & $7 \cdot 6$ & 14.7 & $7 \cdot 4$ \\
\hline 116 & 7 & $14 \cdot 4$ & $7 \cdot 1$ & 15.9 & 7.5 \\
\hline 121 & 12 & 16.5 & 7.9 & $15 \cdot 7$ & $7 \cdot 8$ \\
\hline 123 & 11 & 15.9 & $7 \cdot 6$ & 14.8 & 7.5 \\
\hline 128 & 6 & 15.9 & $7 \cdot 6$ & 14.7 & $7 \cdot 4$ \\
\hline
\end{tabular}

offspring on mid-parental value. The method minimises the effects of assortative mating on the estimate and in fact actually reduces the sampling variance of the regression coefficient by increasing the variance of midparental values (Falconer, 1960).

The regression coefficient is then a direct measure of heritability: $b=h^{2}$. Although the regression coefficient may take any value, when it expresses 
heritability we expect it to fall in the interval from 0 to +1 . The latter value represents a slope of $45^{\circ}$, when unit increments among the offspring follow from unit increments of the mid-parental measurement. In practice, occasional values of $b$ may exceed unity.

The four basic estimates are the regressions of offspring on mid-parent for length and width in each of the two species of Partula. Before proceeding to these calculations, however, we must consider several factors which may influence the results.

Two of them may be considered together. They are (1) the possibility that there is a direct maternal effect on shell size and (2) the possibility of

TABLE 3

An analysis of variance comparing the length of offspring of two colour types (purple and yellow) from each of the two barents of mating 2 of Partula taeniata

$\begin{array}{lrcr}\begin{array}{l}\text { Source of } \\ \text { variation }\end{array} & \begin{array}{r}\text { Sums of } \\ \text { squares }\end{array} & \begin{array}{c}\text { Degrees of } \\ \text { freedom }\end{array} & \begin{array}{c}\text { Mean } \\ \text { square }\end{array} \\ \text { Parents } & 0.092 & 1 & 0.092 \\ \text { Colours } & 0.175 & 1 & 0.175 \\ \text { Interaction } & 0.003 & 1 & 0.003 \\ \text { Error } & 27.590 & 44 & 0.627 \\ \text { Total } & 27.860 & 47 & -\end{array}$

TABLE 4

An analysis of variance comparing the length of offspring of two pattern types (banded and unbanded) from each of the two parents of mating 6 of Partula taeniata

$\begin{array}{lrcr}\begin{array}{l}\text { Source of } \\ \text { variation }\end{array} & \begin{array}{r}\text { Sums of } \\ \text { squares }\end{array} & \begin{array}{c}\text { Degrees of } \\ \text { freedom }\end{array} & \begin{array}{r}\text { Mean } \\ \text { square }\end{array} \\ \text { Parents } & 0.090 & 1 & 0.090 \\ \text { Pattern } & 1.361 & 1 & 1.361 \\ \text { Interaction } & 0.188 & 1 & 0.188 \\ \text { Error } & 19.687 & 32 & 0.615 \\ \text { Total } & 21.326 & 35 & -\end{array}$

an association within broods between size and colour or pattern. Partula is particularly favourable for a study of maternal effects because every mating results in two groups of offspring, one from each parent. Since the two groups are genetically equivalent, they may be used to test differences in the maternal contribution to the phenotype. A test for association between the size of a shell and its colour or pattern is prompted by the discovery that in some wild populations of $P$. taeniata such associations exist (Glarke and Murray, in preparation).

The association of size with maternal parent and with colour or pattern has been tested in $P$. taeniata by two-way analyses of variance (see tables 3 and 4). In table 3 comparisons of length are made among groups of offspring of mating 2 of $P$. taeniata with respect to parent and colour. The mating was chosen for (1) a large difference in length between parents, (2) a backcross segregation of brownish-purple (N4) and yellow (Y1) offspring (for scoring of colour see Murray and Clarke, 1966) and (3) large 
numbers of offspring evenly divided among the various classes. The analysis indicates that there is no reason to suspect any maternal effect on size or any association between size and colour.

Table 4 shows a similar analysis of mating 6 in $P$. taeniata with respect to shell pattern. The offspring are segregating for banded $v$. unbanded shells. Again there is no evidence of association of size with maternal parent or shell pattern.

In $P$. suturalis none of the matings combines all of the favourable characteristics listed above for carrying out an analysis of variance on size, parent and shell pattern. Consequently we have simply tested, in two matings, the difference between the mean length of the offspring from the two parents. The difference in mating 25 is not significant, but in mating 28 the value of $t$ reaches the 5 per cent. level of significance. We are inclined to discount the latter result, however, since the difference is contrary to expectation on the hypothesis of a maternal effect. It is in fact the smaller parent which has produced the larger offspring. Since the larger parent bore a larger number of young, their smaller size may have resulted from relatively more crowded conditions during rearing. It seems reasonable to conclude, therefore, that there is no detectable maternal influence on size apart from the expected genetic contribution.

The environmental conditions in the rearing boxes may be responsible for another unexpected result. Tables 1 and 2 show that the mean size of the offspring in both species tends to be smaller than the parental midpoint. This effect is significant in $P$. suturalis $(\mathrm{P}<0.01)$ but not in $P$. taeniata. Since the tables do not suggest that the broods of larger and smaller parents are differentially affected in this respect, the estimates of heritability are not likely to be altered.

Another problem to be considered in the calculation of regressions is the question of variable family size. Perhaps the simplest answer would be to choose randomly a fixed number of offspring from each family. This method, however, ignores much of the data. Reeve (1955) discusses three possible approaches:

(1) To give equal weights to families of all sizes.

(2) To give weights proportional to the number of offspring.

(3) To give weights producing the minimum variance of regression coefficients.

Each method suffers from certain drawbacks. Obviously the larger families will yield more precise estimates of offspring means than will small families. The increase in precision, however, is not related linearly to the increase in numbers of progeny. With respect to the third method of weighting, there is uncertainty how the value of $T$, on which the calculation of weights depends, is to be fixed. Consequently it seems that a prudent course would be to use equal weights for all families while restricting the analysis to families of five or greater. In the event, the smaller families seem to be consistent with the rest.

The final question to be considered is whether there is a consistent difference of heritability between those families produced by parents collected in the wild and those produced by parents reared entirely under laboratory conditions. We calculated a preliminary set of four pairs of regression coefficients for length and width in $P$. suturalis and $P$. taeniata. 
In each case the regression of offspring mean on mid-parent for broods with wild-caught parents was compared with the similar regression for broods with laboratory-reared parents (table 5).

The values of the eight regression coefficients range from 0.28 for length in the $\mathrm{F}_{1}$ of $P$. taeniata to 1.29 for length in the $\mathrm{F}_{1}$ of $P$. suturalis. All these values are positive, and six are significantly different from zero. The two lowest values, for width in the $\mathrm{F}_{2}$ of $P$. suturalis and for length in the $\mathrm{F}_{1}$ of $P$. taeniata, do not reach the 5 per cent. level of significance. In the comparisons of heritability between broods with wild-caught parents and lab-reared parents, there is no consistent trend. Three of the comparisons show a decrease of heritability in $F_{2}$ from $F_{1}$ while one shows an increase. In three of the comparisons, the difference between the $F_{1}$ and the $F_{2}$ broods is not significant. In the fourth case, width in $P$. suturalis, the probability that the observed difference is due to chance alone lies between 5 and 2 per cent.

\section{TABLE 5}

Regression coefficients, with 95 per cent. confidence limits, of mean length and width of offspring on mid-parental values. The $F_{1}$ and $F_{2}$ are shown separately and also combined. The value for the combined regression for width in P. suturalis is enclosed in brackets to indicate that this combination is not strictly legitimate

$\begin{array}{lccc} & \begin{array}{c}\text { Wild-caught } \\ \text { parents }\end{array} & \begin{array}{c}\text { Lab-reared } \\ \text { parents }\end{array} & \text { Combined } \\ \begin{array}{l}\text { Partula suturalis } \\ \text { Length }\end{array} & 1 \cdot 29 \pm 0.53 & 1 \cdot 12 \pm 0.41 & 0.81 \pm 0.42 \\ \text { Width } & 0.98 \pm 0.13 & 0.31 \pm 0.20 & (0.53 \pm 0.13) \\ & & & \\ \text { Partula taeniata } & & & \\ \quad \text { Length } & 0.28 \pm 0.33 & 0.41 \pm 0.17 & 0.36 \pm 0.17 \\ \text { Width } & 0.60 \pm 0.07 & 0.36 \pm 0.07 & 0.40 \pm 0.14\end{array}$

In three of the four cases, therefore, it is permissible to use the data for the two generations for combined estimates of heritability. In the fourth case, taking into account the moderate level of significance and the inconsistency of the trends in the four pairs of regressions, we have calculated the combined estimate although the indication of heterogeneity makes this a questionable procedure. These estimates, ranging from 0.36 for length in $P$. taeniata to $0 \cdot 81$ for length in $P$. suturalis, are shown in the third column of table 5 .

These combined regressions are displayed in figs. 2 and 3 for $P$. suturalis and $P$. taeniata respectively. In the case of width in $P$. suturalis the points derived from $F_{1}$ and $F_{2}$ families are given different symbols.

The results indicate a high degree of genetic control over variation in size of the shell in Partula. To what extent can these estimates be applied to natural populations? Obviously the carry-over is limited. Even those parents which were collected in the wild were taken as young animals, and they completed their growth under artificial conditions. They were, however, subjected to a wide range of environmental conditions, in the transfer from field to holding boxes and finally to the laboratory. The fact that high heritabilities were expressed under these conditions gives us some confidence that if estimates under field conditions were possible, they would produce comparable values. 


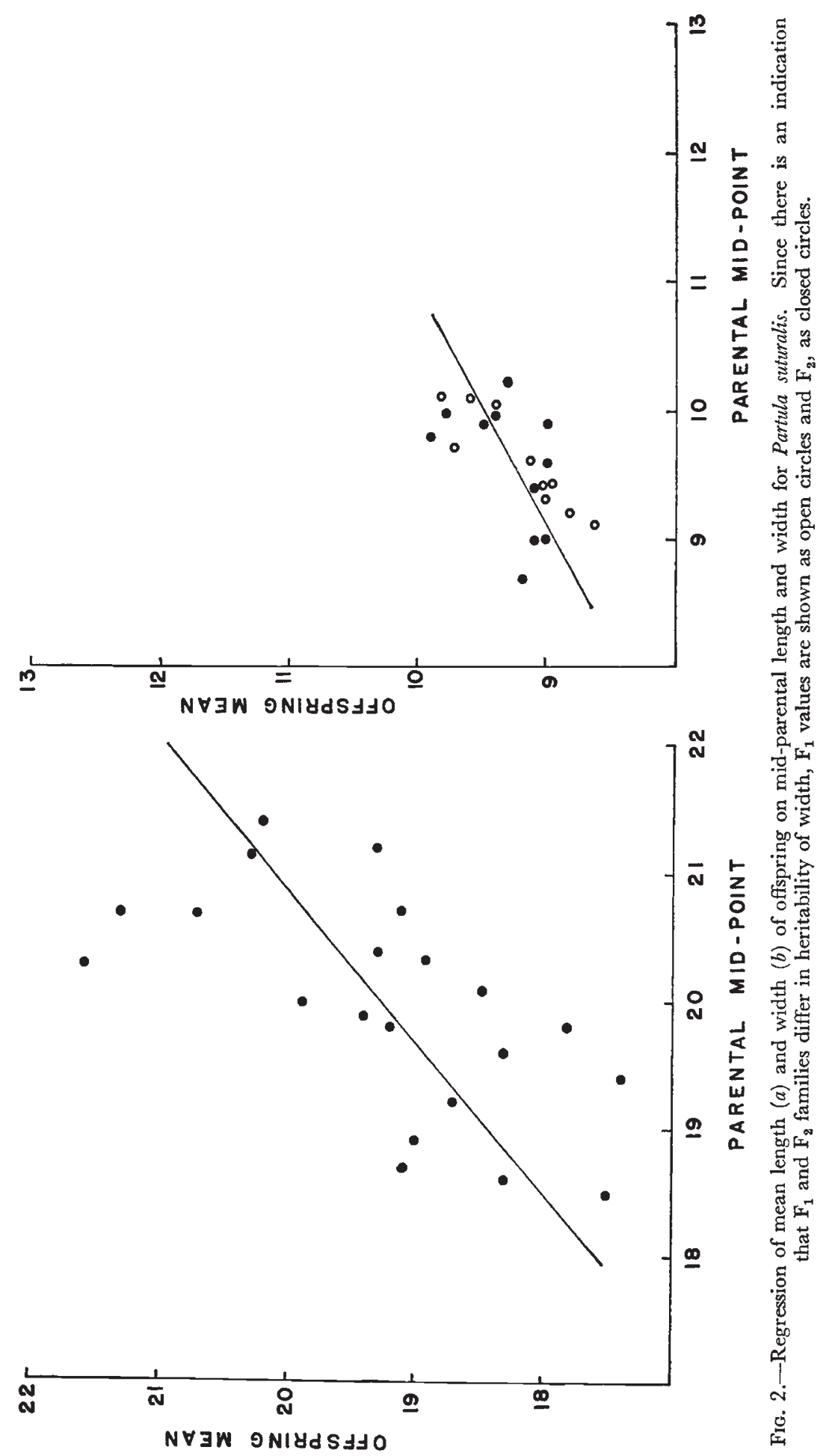




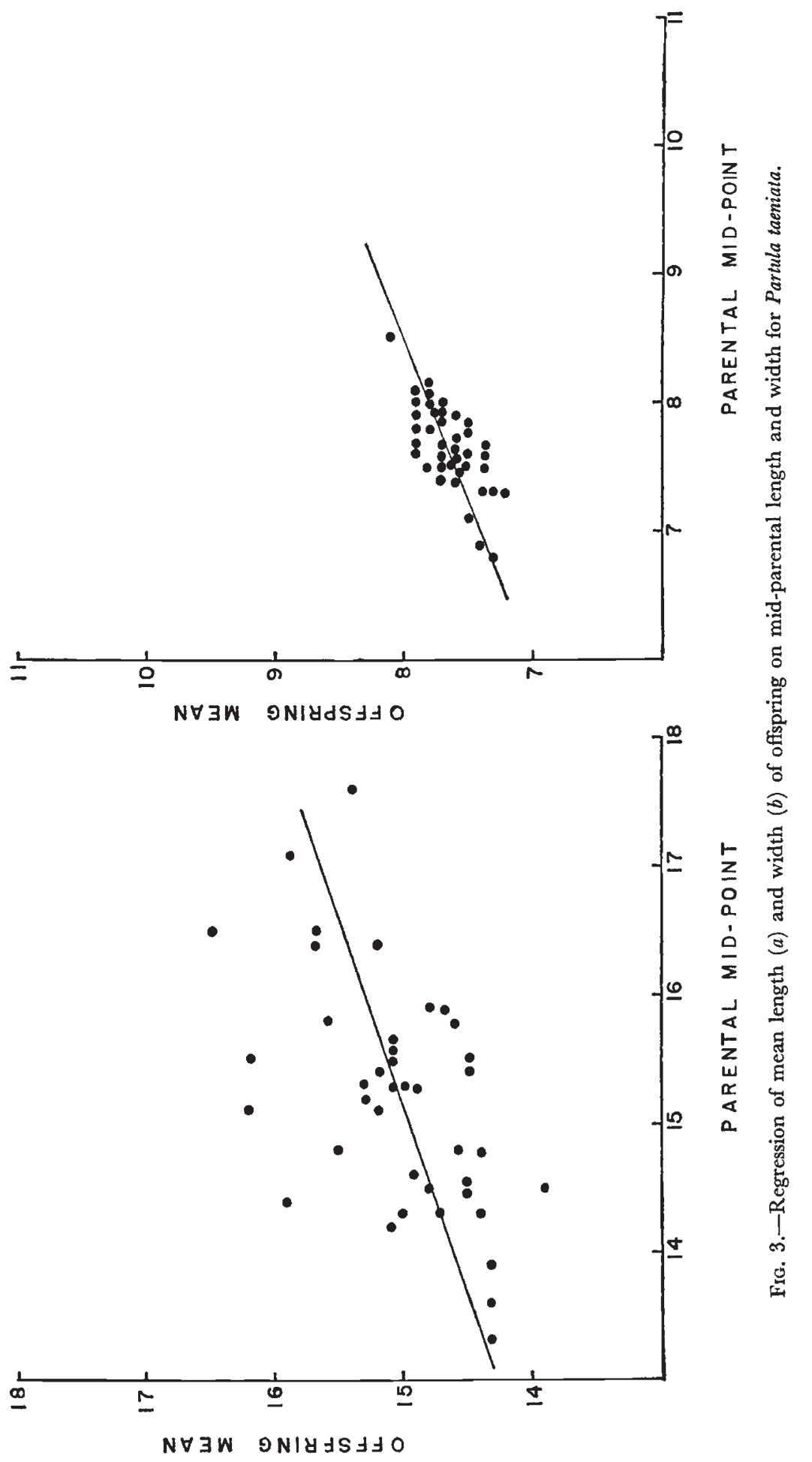


With respect to the selective value of size in Partula, high heritability indicates that within the population there is a store of additive genetic variance and that the population is capable of responding to directional selection for the character. By reversing the argument we may infer that any selection operating on the dimensions of the shell in these species of Partula is likely to be stabilising rather than directional.

\section{SUMmary}

1. The heritability of shell size in $P$. suturalis and $P$. taeniata has been measured by the regression of mean length and width of offspring on parental midpoints. The heritabilities (table 5) are high.

2. In one of the four cases heritability was significantly different in the $F_{1}$ and $F_{2}$ generations.

3. We found no evidence of maternal effects on size and no detectable differences in size between colour or banding morphs within broods.

Acknowledgments.-We should like to express our appreciation to Mrs Elizabeth Murray and Mrs Elizabeth Kater for their invaluable help in the rearing of animals. Mrs Kater also assisted in the analysis of the data and in the preparation of the figures. This work was carried out with funds provided by the National Science Foundation (GB-4188). We also wish to thank Professor Dietrich Bodenstein for the facilities which he has provided.

\section{REFERENCES}

Balley, D. W. 1956. Re-examination of the diversity in Partula taeniata. Evolution, 10, 360-366.

GRAMPTON, H. E. 1916. Studies on the variation, distribution, and evolution of the genus Partula. The species inhabiting Tahiti. Carnegie Inst. Wash. Publ., 228, 1-311.

CRAMPTON, H. E. 1925. Studies on the variation, distribution, and evolution of the genus Partula. The species inhabiting the Mariana Islands, Guam and Saipan. Carnegie Inst. Wash. Publ., 228a, 1-116.

CRAMPTON, H. E. 1932. Studies on the variation, distribution, and evolution of the genus Partula. The species inhabiting Moorea. Carnegie Inst. Wash. Publ., 410, 1-335.

FALCONER, D. s. 1960. Introduction to Quantitative Genetics. Oliver and Boyd, Edinburgh and London.

Garrett, A. 1884. The terrestrial mollusca inhabiting the Society Islands. 7. Acad. $\mathcal{N a t}$. Sci. Phila, 2nd series, 9, 17-114.

Hartman, w. D. 1885. Descriptions of new species of Partula and a synonymic catalogue of the genus. Proc. Acad. Nat. Sci. Phil., 37, 203-223.

Lundman, B. 1947. Maps of the racial geography of some Partulae of the Society Islands based upon the material published by H. E. Crampton. Zool. Bidrag Uppsala, 25, $517-533$

MURRAY, J., AND GLARKE, B. 1966. The inheritance of polymorphic shell characters in Partula (Gastropoda). Genetics, 54, 1261-1277.

REEve, E. C. R. 1955. The variance of the genetic correlation coefficient. Biometrics, 11 , 357-374. 